Brazilian Journal

of Chemical

Engineering

\title{
COMPETING SOLVENT EXTRACTION OF CALCIUM AND/OR NICKEL WITH CYANEX 272 AND/OR D2EHPA
}

\author{
Marcel F. A. de Souza ${ }^{1}$ and Marcelo B. Mansur ${ }^{2 *}$ \\ ${ }^{1}$ Universidade Federal de Minas Gerais, Programa de Pós-graduação em Engenharia Metalúrgica, Materiais e de Minas, \\ Belo Horizonte, MG, Brasil. \\ ${ }^{2}$ Universidade Federal do Rio de Janeiro, Programa de Pós-graduação em Engenharia Metalúrgica e de Materiais, \\ Rio de Janeiro, RJ, Brasil. E-mail: marcelo.mansur@metalmat.ufrj.br, ORCID: 0000-0003-4916-5028
}

(Submitted: October 18, 2017 ; Revised: January 25, 2018 ; Accepted: March 4, 2018)

\begin{abstract}
The present study assessed the competing behavior between metals and extractants applied to the solvent extraction of calcium and/or nickel present in sulfuric solutions using the extractants Cyanex 272 (bis2,4,4-trimethylpentyl phosphinic acid) and/or D2EHPA (di-2-ethylhexyl phosphoric acid). Tests were designed to allow equivalent competing conditions between metals and extractants. Considering metal competition in the aqueous phase, calcium extraction remained unaffected in the presence of nickel, while nickel extraction curves with $\mathrm{pH}$ displaced to the right in the presence of calcium when D2EHPA $\left(\Delta \mathrm{pH}_{1 / 2}=1.4\right)$ or Cyanex $272+$ D2EHPA $\left(\Delta \mathrm{pH}_{1 / 2}=0.9\right)$ were used. Considering extractant competition in the organic phase, metal extractions with Cyanex 272 + D2EHPA closely followed the curves obtained with D2EHPA, thus evidencing that it acts as the main extractant agent, synergism or antagonism effects being attributed to the presence of Cyanex 272. A synergistic increase in the calcium extraction occurred at $\mathrm{pH} \geq 4.5$, being unaffected in the presence of nickel, whereas rejection for nickel occurred in the whole $\mathrm{pH}$ range in the absence of calcium, and at $\mathrm{pH}<5.5$ in the presence of calcium. For the operating conditions investigated, $\mathrm{Ca} / \mathrm{Ni}$ separation reached a maximum at $\mathrm{pH}=4.5$ (calcium extraction $>80 \%$, nickel extraction $<0.25 \%, \beta_{\mathrm{CaNi}}=2159$ ).

Keywords: Synergistic solvent extraction; Cyanex 272; D2EHPA; Calcium; Nickel.
\end{abstract}

\section{INTRODUCTION}

The extractant Cyanex 272 (bis-2,4,4trimethylpentyl phosphinic acid) is commercially used to selectively separate cobalt and nickel from sulfate leaching liquors. The removal of calcium, however, does not occur with this reagent (Guimarães et al., 2014); hence, calcium goes with nickel to the electrowinning step. The formation of precipitates depending on the metal concentration levels, as well as the higher consumption of current in the electrowinning step in the presence of magnesium in the liquor must be considered. According to Dutrizac and Kuiper (2006), the deposit of calcium on the diaphragms of electrowinning baths requires higher voltages to overcome the increased electrical resistance of the diaphragm, including a subsequent increase in the voltage distribution within the cell and a disturbance of the cathode potential necessary for the deposit of nickel metal from the catholyte. Therefore, such alkaline earth metals need to be removed using the hydrometallurgical nickel-refining route.

For concentrated nickel sulfate solutions similar to MHP (mixed-hydroxide precipitation) intermediate solutions $\left([\mathrm{Ca}]=0.5 \mathrm{~g} \cdot \mathrm{L}^{-1},[\mathrm{Mg}]=3.1 \mathrm{~g} \cdot \mathrm{L}^{-1}\right.$, and $[\mathrm{Ni}]=$ $88 \mathrm{~g} \cdot \mathrm{L}^{-1}$ ), D2EHPA (di-2-ethylhexyl phosphoric acid, $10 \% \mathrm{v} / \mathrm{v}$ or $0.3 \mathrm{M}$ in Exxsol D80, A/O ratio $=1, \mathrm{~T}=50$ ${ }^{\circ} \mathrm{C}$ ) has proven to be a selective reagent for removing calcium at $3.0<\mathrm{pH}<3.5(72 \%$ extraction in one single contact, $\left.\beta_{\mathrm{CaNi}}=78-173\right)$; however, at higher $\mathrm{pH}$

\footnotetext{
* Corresponding author: Marcelo B. Mansur - E-mail: marcelo.mansur@metalmat.ufrj.br
} 
values, the extraction of calcium drops substantially due to the crowding out effect of nickel. Alternatively, the extraction of magnesium with Cyanex $272(10 \%$ $\mathrm{v} / \mathrm{v}$ or $0.32 \mathrm{M}$ in Exxsol D80, $\mathrm{A} / \mathrm{O}$ ratio $=1, \mathrm{~T}=50^{\circ} \mathrm{C}$ ) increases with $\mathrm{pH}$, reaching approximately $70 \%$ in one single contact at $\mathrm{pH} \approx 5.7$, whereas nickel extraction does not surpass $5 \%\left(\beta_{\mathrm{Mg} / \mathrm{Ni}}=75\right)$. At $\mathrm{pH}>6$, a large quantity of nickel is extracted, forming a crud in the organic phase that limits operation (Guimarães and Mansur, 2017).

The mixture of cationic extractants (organophosphorous and carboxylic acid) aiming to enhance the $\mathrm{Co} / \mathrm{Ni}$ separation in the presence of calcium has been investigated in a series of studies carried out at Mintek using organic reagents acting as an adduct, including oximes (Preston, 1983), pyridine-carboxylate esters (Preston and Du Preez, 1994, 1996), and alkyl-pyridines (Preston and Du Preez, 2000). Synergistic systems were also investigated in the presence of calcium, magnesium, and other metal species commonly found in the laterite HPAL (high pressure acid leaching) or MHP (mixed hydroxide precipitate) leaching solutions (Tsakiridis and Agatzini, 2004; Preston and Du Preez, 2004; Cheng, 2006; Ndlovu and Mahlangu, 2008; Cheng et al., 2010, 2015; Guan et al., 2016). Recently, Guimarães and Mansur (2018) observed that calcium and magnesium are preferentially extracted over nickel when D2EHPA $(5-20 \% \mathrm{v} / \mathrm{v})$ is mixed with Cyanex $272(20 \% \mathrm{v} / \mathrm{v})$. This synergistic system, composed of commercial extractants, is highly dependent on the aqueous $\mathrm{pH}$ and the organic phase composition. In the most selective condition, approximately $70 \%$ of calcium $\left(\beta_{\mathrm{CaNi}}=124\right)$ and $40 \%$ of magnesium $\left(\beta_{\mathrm{Mg} / \mathrm{Ni}}=28\right)$ were extracted $(\mathrm{pH}=3.5$, $[\mathrm{D} 2 \mathrm{EHPA}]=10 \% \mathrm{v} / \mathrm{v}, \mathrm{A} / \mathrm{O}$ ratio $\left.=1, \mathrm{~T}=50^{\circ} \mathrm{C}\right) . \mathrm{In}$ this condition, synergism occurred for calcium and magnesium, whereas antagonism occurred for nickel. The crowding out effect of calcium due to the nickel extraction, as well as the crud formation at $\mathrm{pH}>6$, was also verified; however, this synergistic system was found to be more selective than using Cyanex 272 and D2EHPA separately. The synergistic effects may occur due to competing interaction between metals and extractants present in both liquid phases.

Aiming to gain a better understanding of such complex effects, the present study was performed using calcium and/or nickel in the aqueous phase, and Cyanex 272 and/or D2EHPA in the organic phase. The concentration levels of each species present in the same liquid phase were chosen to allow equivalent competing conditions, to avoid preference of an extractant to extract a given metal species and also the occurence of a crowding out effect of calcium by nickel extraction.

\section{MATERIALS AND METHODS}

\section{Reagents and solutions}

The aqueous phase used in this study was achieved by dissolving a given weighed mass of each metal ion sulfate salt (Synth, analytical grade $>98 \%$ ) in deionized water, containing $\mathrm{H}_{2} \mathrm{SO}_{4}$ (Synth, purity $95 \%$ ), $\mathrm{pH} \approx$ 3.5 , which was filtered to remove any precipitated species. The organic phases were prepared by mixing the extractants Cyanex 272 (Cytec, purity 85\%) and/or D2EHPA (Baysolvex-Lanxess Energizing Chemistry, purity 95\%) in n-heptane (Synth, purity 99\%). The structures of the extractants are shown in Figure 1. All reagents were used as received.

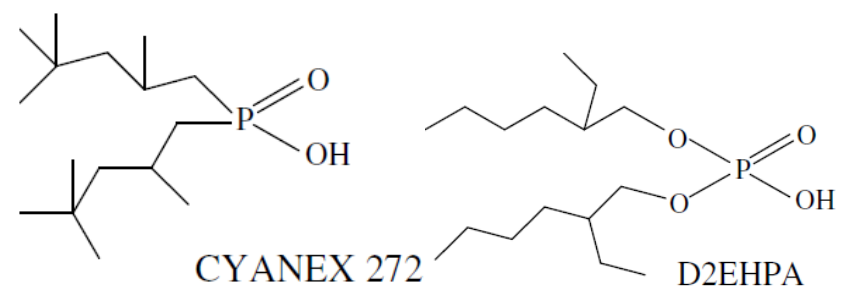

Figure 1. Molecular structure of extractants Cyanex 272 and D2EHPA.

\section{Solvent extraction tests}

Aiming to evaluate the interactions between the competing species in both aqueous and organic phases, tests were designed according to the following steps:

- Step 1: Interaction between one metal and one extractant: in these tests, the aqueous phase contained only calcium or nickel, and the organic phase contained only Cyanex 272 or D2EHPA;

- Step 2: Interaction between two metals and one extractant: in these tests, the aqueous phase contained both calcium and nickel at similar molar concentrations, and the organic phase contained only Cyanex 272 or D2EHPA;

- Step 3: Interaction between one metal and two extractants: in these tests, the aqueous phase contained only calcium or nickel, and the organic phase contained both Cyanex 272 and D2EHPA at similar molar concentrations;

- Step 4: Interaction between two metals and two extractants: in these tests, the aqueous phase contained both calcium and nickel at similar concentrations, and the organic phase contained both Cyanex 272 and D2EHPA at similar concentrations.

The concentration levels used in the tests of each step were chosen to allow equivalent competing conditions (same concentrations for calcium and nickel, as seen in Table 1) and to avoid the crowding out effect of the extracted calcium that occurs when higher concentrations of nickel are involved (Guimarães and Mansur, 2018). The low solubility of $\mathrm{CaSO}_{4}$ in water $\left(0.017 \mathrm{~mol} \cdot \mathrm{L}^{-1}\right.$ at $\left.20^{\circ} \mathrm{C}\right)$ was then considered to define the metal concentrations used in the present study. 
Table 1. Initial composition of the aqueous and organic phases.

\begin{tabular}{|c|c|c|c|c|c|}
\hline \multirow[t]{2}{*}{ Step } & \multirow{2}{*}{$\begin{array}{l}\text { Notation } \\
\text { (used in the legends of figures) }\end{array}$} & \multicolumn{2}{|c|}{$\begin{array}{l}\text { Aqueous phase } \\
\left(\mathrm{mol}^{\left.-\mathrm{L}^{-1}\right)}\right.\end{array}$} & \multicolumn{2}{|c|}{$\begin{array}{l}\text { Organic phase } \\
\left(\mathrm{mol}^{\left.-\mathrm{L}^{-1}\right)}\right.\end{array}$} \\
\hline & & $\mathrm{Ca}$ & $\mathrm{Ni}$ & Cyanex 272 & D2EHPA \\
\hline \multirow{4}{*}{1} & (Ca), (Cyanex 272) & 0.01 & - & 0.05 & - \\
\hline & (Ca), (D2EHPA) & 0.01 & - & - & 0.05 \\
\hline & (Ni), (Cyanex 272) & - & 0.01 & 0.05 & - \\
\hline & (Ni), (D2EHPA) & - & 0.01 & - & 0.05 \\
\hline \multirow{2}{*}{2} & $(\mathrm{Ca}+\mathrm{Ni}),($ Cyanex 272) & 0.01 & 0.01 & 0.05 & - \\
\hline & $(\mathrm{Ca}+\mathrm{Ni}),(\mathrm{D} 2 \mathrm{EHPA})$ & 0.01 & 0.01 & - & 0.05 \\
\hline \multirow{2}{*}{3} & (Ca), (Cyanex $272+$ D2EHPA $)$ & 0.01 & - & 0.05 & 0.05 \\
\hline & (Ni), (Cyanex $272+$ D2EHPA $)$ & - & 0.01 & 0.05 & 0.05 \\
\hline 4 & $(\mathrm{Ca}+\mathrm{Ni}),($ Cyanex $272+\mathrm{D} 2 \mathrm{EHPA})$ & 0.01 & 0.01 & 0.05 & 0.05 \\
\hline
\end{tabular}

Once calcium is removed, the content of nickel in the purified solution is not adequate for electrowinning and it has to be subsequently improved by using, for example, solvent extraction with Cyanex 272, as proposed by Agatzini-Leonardou et al. (2009). $\mathrm{Li}_{2} \mathrm{SO}_{4}$ was added to the aqueous phases aiming to maintain the ionic strength constant $\left(\mathrm{I}=0.25 \mathrm{~mol} \cdot \mathrm{L}^{-1}\right)$ in all tests. According to the literature (Mantuano et al., 2006; Bukowsky et al., 1992), lithium is not extracted by Cyanex 272 or D2EHPA $\left(1 \leq \mathrm{pH} \leq 7, \mathrm{~T}=25^{\circ} \mathrm{C}\right)$, and in the tests, it was below $1 \%$.

Tests were performed by contacting $150 \mathrm{~mL}$ of both aqueous and organic phases $(\mathrm{A} / \mathrm{O}$ ratio $=1)$ in a covered glass reactor of $1 \mathrm{~L}$ provided with a stainless steel marine-type impeller and a $\mathrm{pH}$ electrode (Digimed, DM-22) attached to a temperature electrode for $\mathrm{pH}$ control. The reactor was immersed in a controlled temperature bath, $\mathrm{T}=(25 \pm 2){ }^{\circ} \mathrm{C}$, and both phases were mechanically mixed at a constant stirring speed of $400 \mathrm{rpm}$. After mixing for $10 \mathrm{~min}$, the mixture was allowed to stand for $5 \mathrm{~min}$ for phase separation, and the $\mathrm{pH}$ of the aqueous phase was measured. Samples of both phases $(5 \mathrm{~mL})$ were withdrawn at $\mathrm{pH}$ intervals of approximately 0.75 . Sodium hydroxide (Synth, analytical grade, $98 \%$ purity) solution $\left(10 \mathrm{~mol} \cdot \mathrm{L}^{-1}\right)$ was used to adjust the $\mathrm{pH}$ of the aqueous phase to the required value. The concentrations of metal species in the aqueous phase were analyzed by atomic absorption (GBC, model XplorAA dual), and their respective concentrations in the organic phase were determined by mass balance. No third phase was observed in the studied conditions and some tests were performed in duplicate to evaluate reproducibility.

\section{RESULTS AND DISCUSSION}

In all operating conditions studied in the present work, the typical behavior of cationic extractants was verified. In fact, the extraction curves of calcium and/or nickel by Cyanex 272 and/or D2EHPA, that is, the extractive affinity of both extractants for both metals, increased with the $\mathrm{pH}$ of the aqueous phase. No crowding out effect between metals occurred, presumably because metal concentrations were low. Moreover, the preferential extraction of calcium over nickel using both organophosphorous extractants for a given $\mathrm{pH}$ level was observed, thus corroborating previous studies (Flett, 2005; Guimarães et al., 2014).

The extraction curves of calcium or nickel (one single metal in the aqueous phase) with Cyanex 272 or D2EHPA (one single extractant in the organic phase) are shown in Figure 2. It can be seen that the affinity of D2EHPA for both metals is comparatively higher than that of Cyanex 272, that is, D2EHPA extracts more calcium or nickel than Cyanex 272 for a given $\mathrm{pH}$ level. The higher affinity of D2EHPA for the metal species is a consequence of its stronger acidic character (phosphoric acid) compared to Cyanex 272 (phosphinic acid), due to the presence of oxygen atoms bonding to the phosphorus atom and the alkyl radicals. In particular, approximately $60 \%$ of calcium was extracted by D2EHPA at $\mathrm{pH}=3.5$; this value remained higher at greater $\mathrm{pH}$ until calcium was completely extracted at $\mathrm{pH} \geq 6.5$. With Cyanex 272, almost $10 \%$ of calcium was extracted at $\mathrm{pH}=5.5$, reaching $65 \%$ of extraction at $\mathrm{pH}=7.0$. Considering nickel, extractions with D2EHPA are also higher than those with Cyanex 272 at the same $\mathrm{pH}$ level. The nickel extractions increased from $10 \%$ to $96.5 \%$ with D2EHPA when the $\mathrm{pH}$ of the aqueous phase rose from 3.5 to $7.0\left(\mathrm{pH}_{1 / 2}=\right.$

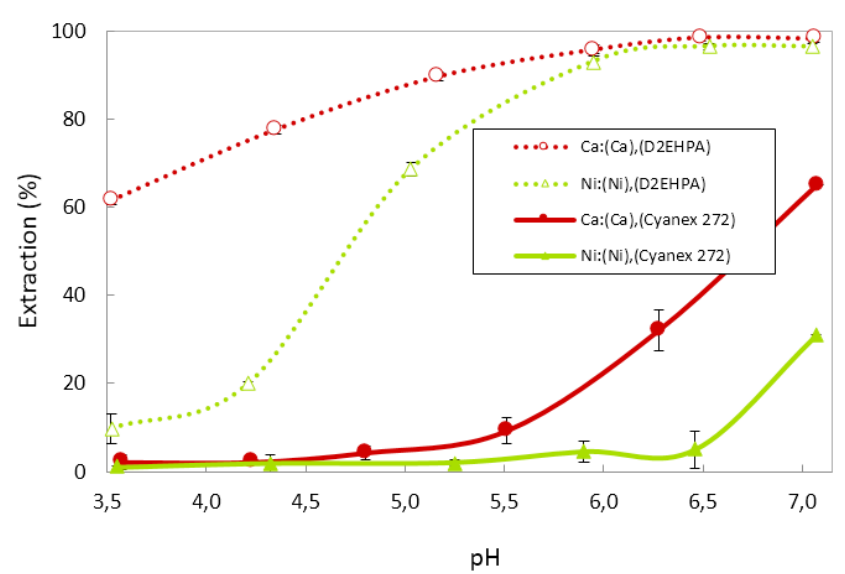

Figure 2. Extraction of calcium or nickel with Cyanex 272 or D2EHPA $\left(A / O=1 ; \mathrm{T}=25^{\circ} \mathrm{C}\right)$. 
4.7 , defined as the $\mathrm{pH}$ at which $50 \%$ of extraction is verified), whereas it increased from less than $5 \%$ at $\mathrm{pH}$ $\leq 6.5$ to $31 \%$ at $\mathrm{pH}=7.0$ with Cyanex 272 .

\section{Metal competition in the aqueous phase}

The competition between calcium and nickel in the aqueous phase to react with extractant(s) can be evaluated by comparing the results obtained in the tests using similar organic phase compositions, that is, steps 1 and 2 with one single extractant (Cyanex 272 or D2EHPA), and steps 3 and 4 with two extractants (Cyanex 272 + D2EHPA). In the operating conditions studied, the extraction of calcium with Cyanex 272 (red curves in Figure 3a), D2EHPA (red curves in Figure 3b), or Cyanex 272 + D2EHPA (red curves in Figure $3 \mathrm{c}$ ) was practically unaffected by the presence of nickel in the aqueous phase at similar dilute concentrations $\left([\mathrm{Ca}]=[\mathrm{Ni}]=0.01 \mathrm{~mol} \cdot \mathrm{L}^{-1}\right)$. This result is due to the higher affinity of both extractants for calcium over nickel. Moreover, it explains the behavior of the extraction curves of nickel obtained with Cyanex 272 (green curves in Figure 3a), D2EHPA (green curves in Figure 3b), or Cyanex 272 + D2EHPA (green curves in Figure 3c). In particular, as calcium is preferentially extracted, a lower concentration of free extractant reacts with nickel; hence, the extraction curves of nickel in the presence of calcium at similar concentration levels are displaced to the right. This behavior is clearly observed when the organic phase contains D2EHPA (Figures $3 \mathrm{~b}$ and $3 \mathrm{c}$ ), because its affinity to calcium is relatively higher than that of Cyanex 272.

The $\mathrm{pH}$ effect of the aqueous phase on the selectivity of $\mathrm{Ca} / \mathrm{Ni}$ (defined as $\beta_{\mathrm{CaNi}}=\mathrm{D}_{\mathrm{Ca}} / \mathrm{D}_{\mathrm{Ni}}$, where $\mathrm{D}_{\mathrm{M}}$ is the distribution ratio of species $\mathrm{M}$ between the organic and the aqueous phases) is presented in Table 2. It increases with $\mathrm{pH}$ because higher extractions of calcium are obtained until reaching a maximum, and then decreases because the extraction of nickel becomes significative at higher $\mathrm{pH}$ levels. Cyanex 272 is not very selective for $\mathrm{Ca} / \mathrm{Ni}$ separation from sulfate solutions $\left(\beta_{\mathrm{CaNi}}<15\right)$; in particular, extremely close dashed curves as shown in Figure 3(a) exist between both metals, corroborating the literature (Flett, 2005; Guimarães et al., 2014). D2EHPA, on the contrary, is a reasonable choice to separate calcium and nickel at $3.5<\mathrm{pH}<5.5$, where $\beta_{\mathrm{CaNi}}$ values ranged from approximately $50-205$; however, the separation $\mathrm{Ca} / \mathrm{Ni}$ was significantly improved at this $\mathrm{pH}$ range by using the mixture Cyanex $272+$ D2EHPA (reaching $\beta_{\mathrm{Ca} / \mathrm{Ni}}=$ 2159 at $\mathrm{pH} 4.5$ ), this result presumably being due to the rejection of nickel by the presence of calcium.

\section{Synergistic extraction analysis}

The same data were plotted in Figure 4 to evidence the synergistic extraction behavior of the extractant
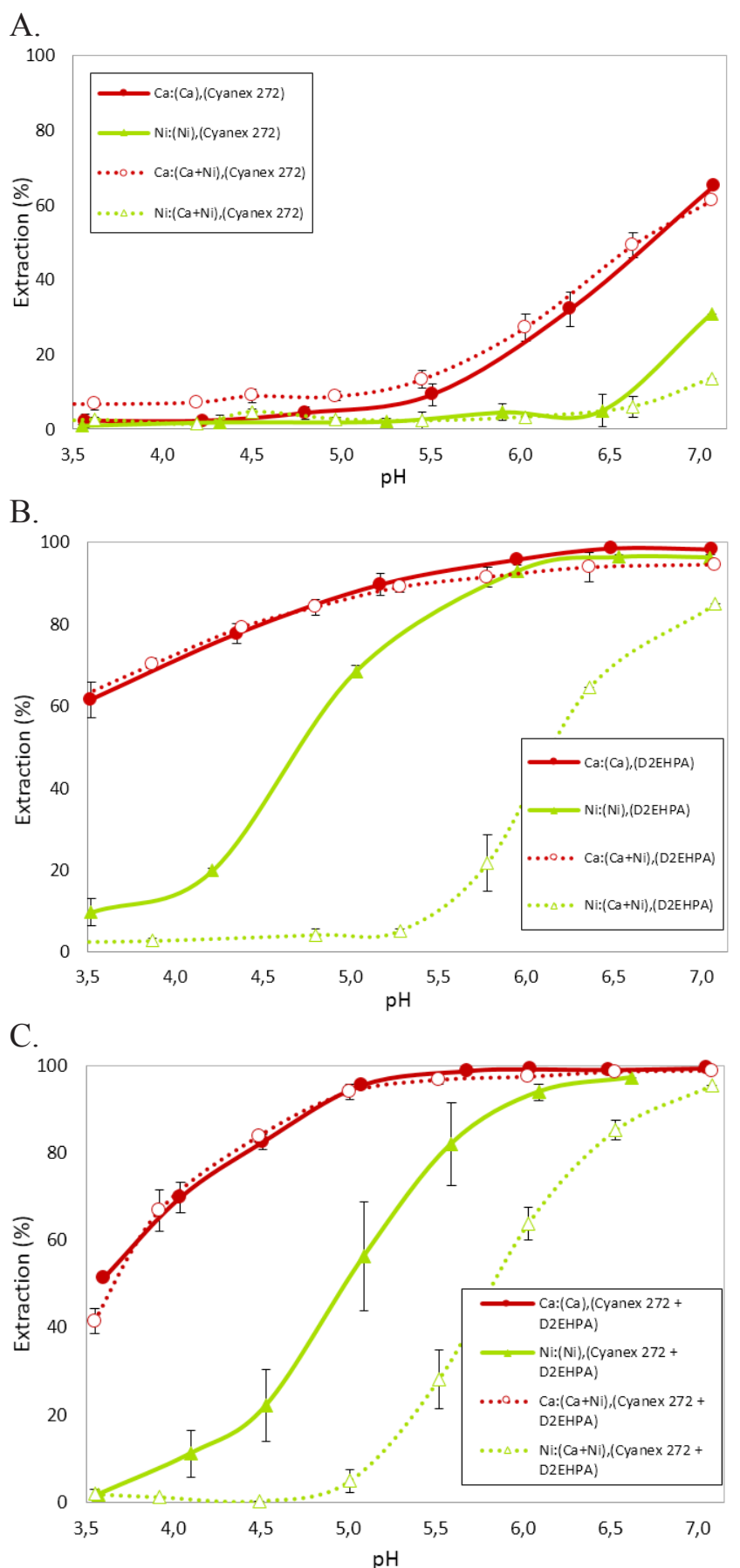

Figure 3. Extraction of calcium and/or nickel from the aqueous solutions containing one or two metal species with (a) Cyanex 272, (b) D2EHPA, and (c) Cyanex $272+$ D2EHPA $\left(\mathrm{A} / \mathrm{O}=1 ; \mathrm{T}=25^{\circ} \mathrm{C}\right)$.

mixture (Cyanex 272 + D2EHPA) in the organic phase for the metal(s) extraction by comparing the results obtained in the tests using an aqueous phase containing one single metal (calcium or nickel, steps 1 and 3 ) or two metals (calcium + nickel, steps 2 and 4). As verified earlier, calcium extraction occurs due to the presence of D2EHPA in the operating conditions studied ([Ca] $\left.=[\mathrm{Ni}]=0.01 \mathrm{~mol} \cdot \mathrm{L}^{-1}\right)$. When the mixture Cyanex $272+$ D2EHPA was used, the extraction of calcium 
Table 2. Selectivity of $\mathrm{Ca} / \mathrm{Ni}$ with the aqueous phase pH using extractants Cyanex 272, D2EHPA, and Cyanex $272+$ D2EHPA $\left(\mathrm{A} / \mathrm{O}=1 ; \mathrm{T}=25^{\circ} \mathrm{C}\right)$.

\begin{tabular}{cccc}
\hline \multirow{2}{*}{$\mathbf{p H}$} & \multicolumn{3}{c}{ Selectivity Ca/Ni $\left(\boldsymbol{\beta}_{\mathrm{Ca} / \mathbf{N i})}\right.$} \\
\cline { 2 - 4 } & Cyanex 272 & D2EHPA & $\begin{array}{l}\text { Cyanex 272 } \\
\text { + D2EHPA }\end{array}$ \\
\hline 3.5 & 3.6 & 50.6 & 103.3 \\
4.0 & 3.0 & 80.2 & 172.6 \\
4.5 & 2.7 & 125.6 & 2159.0 \\
5.0 & 3.2 & 204.6 & 300.9 \\
5.5 & 6.5 & 84.0 & 73.9 \\
6.0 & 13.0 & 22.8 & 21.1 \\
6.5 & 14.5 & 5.1 & 11.6 \\
7.0 & 10.1 & 4.0 & 3.9 \\
\hline
\end{tabular}

A.

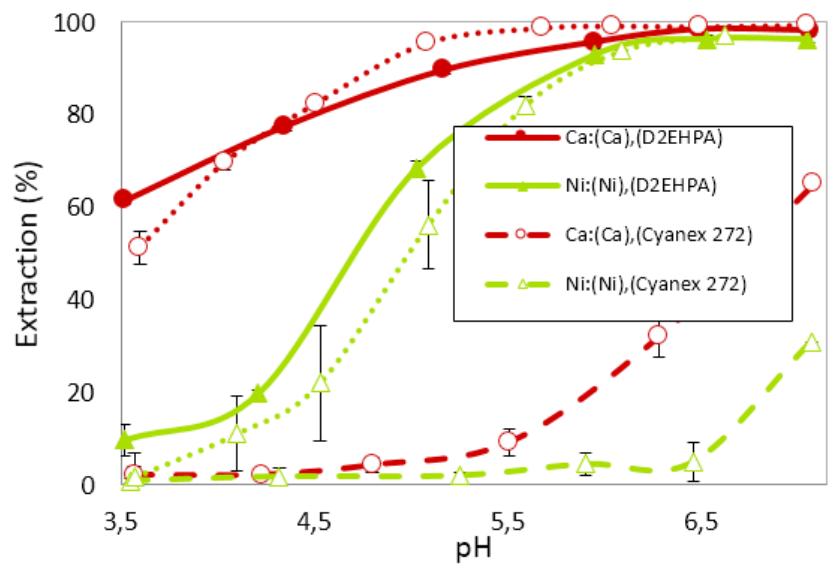

B.

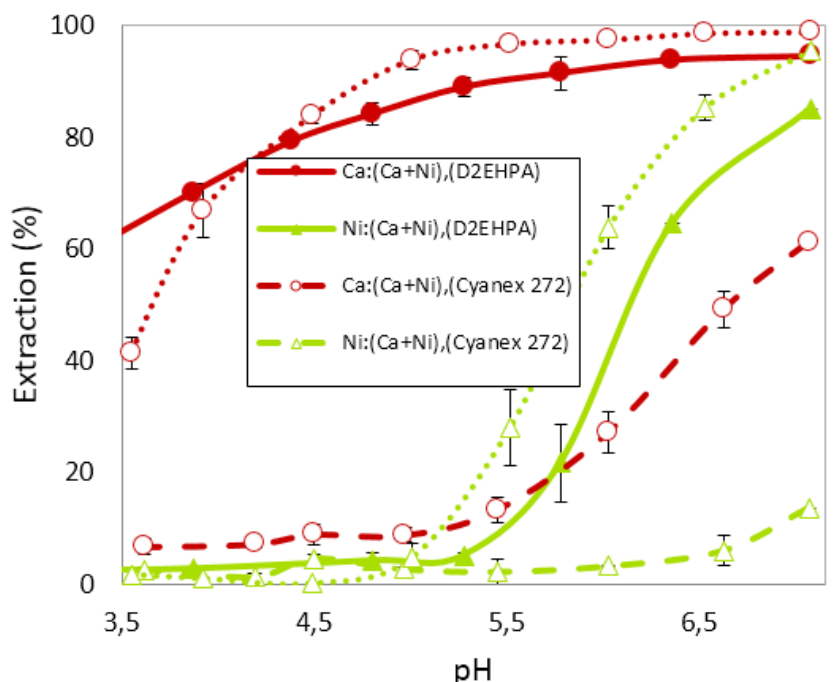

Figure 4. Extraction of calcium and/or nickel with Cyanex 272, D2EHPA, or Cyanex $272+$ D2EHPA: (a) either calcium or nickel in the aqueous phase, (b) calcium and nickel in the aqueous phase $(\mathrm{A} / \mathrm{O}=1 ; \mathrm{T}$ $=25^{\circ} \mathrm{C}$ ).

was negatively affected at $\mathrm{pH}<4.0$ (antagonism) and positively affected at $\mathrm{pH}>4.5$ (synergism), regardless of the absence or presence of nickel in the aqueous solution (red curves in Figure 4a and Figure $4 \mathrm{~b}$, respectively). It can be seen that the addition of
Cyanex 272 is slightly beneficial in extracting calcium when the $\mathrm{pH}$ of the aqueous phase is raised; however, the presence of calcium, on the contrary, affects the extraction of nickel. Compared to the extraction of nickel with D2EHPA, it can be seen that the mixture Cyanex $272+$ D2EHPA results in antagonism in the absence of calcium in the aqueous phase for the whole $\mathrm{pH}$ range investigated (Figure 4a); however, in the presence of calcium in the aqueous phase, the extractive behavior of nickel with the mixture Cyanex $272+$ D2EHPA depends on the $\mathrm{pH}$, where antagonism is observed at $\mathrm{pH}<5$ and synergism at $\mathrm{pH}>5$ (Figure $4 \mathrm{~b})$. Therefore, the selective separation of calcium with the mixture Cyanex 272+D2EHPA in the presence of nickel is favored at $4<\mathrm{pH}<5$.

The effect of the aqueous phase $\mathrm{pH}$ on the synergistic factor of calcium and nickel is presented in Table 3. According to Eq. (1), the synergism effect occurs when the mixture of two different extractants enhances the extraction of a given metal $M$ greatly from the summation of the performance of the two extractants separately (Aguilar and Cortina, 2010). Therefore, antagonism is evidenced by $\mathrm{SF}_{\mathrm{M}}<1$, while synergism by $\mathrm{SF}_{\mathrm{M}}>1$.

$\mathrm{SF}_{\mathrm{M}}=\frac{\mathrm{D}_{\mathrm{M}(\mathrm{Cyanex} 272+\mathrm{D} 2 \mathrm{EHPA})}}{\mathrm{D}_{\mathrm{M}(\mathrm{Cyanex} 272)}+\mathrm{D}_{\mathrm{M}(\mathrm{D} 2 \mathrm{EHPA})}}$

Similar results can be concluded by analyzing the extraction curves of calcium and nickel using the mixture Cyanex $272+$ D2EHPA as shown in Figure 4 and by analyzing the synergistic factors shown in Table 3, that is, (i) the shift from antagonism to synergism on the extractive behavior of calcium at $4.0<\mathrm{pH}<4.5$ caused by the mixture Cyanex $272+$ D2EHPA, regardless of the presence of nickel in the aqueous phase, (ii) the antagonism on the extraction of nickel in the absence of calcium for the whole $\mathrm{pH}$ range investigated, and (iii) the shift from antagonism to synergism on the extraction curve of nickel at 5.0 $<\mathrm{pH}<5.5$ in the presence of calcium. In addition, the ratio between the synergistic factors of calcium and nickel reveals that calcium may be selectively separated in presence of nickel by using the mixture Cyanex $272+$ D2EHPA at $\mathrm{pH} \approx 4.5$.

Interfatial phenomena may explain the shift from antagonism to synergism behavior on the metal extraction with $\mathrm{pH}$ when both extractants are diluted in the organic phase. Using kerosene as a diluent, the liquid-liquid interface is saturated with a monolayer of Cyanex 272 when its concentration is greater than 0.03 $\mathrm{mol} \cdot \mathrm{L}^{-1}$ (Biswas and Singha, 2006), and with D2EHPA at a concentration greater than $0.0045 \mathrm{~mol} \cdot \mathrm{L}^{-1}$ (Biswas et al., 2003). Presumably, both extractants compete to cover the interface because their initial concentrations 
Table 3. Synergistic factor of calcium and nickel with the aqueous phase $\mathrm{pH}$ using extractants Cyanex 272 and D2EHPA $\left(\mathrm{A} / \mathrm{O}=1 ; \mathrm{T}=25^{\circ} \mathrm{C}\right)$.

\begin{tabular}{ccccccc}
\hline \multirow{2}{*}{$\mathbf{p H}$} & \multicolumn{2}{c}{ Aqueous phase containing Ca or Ni } & \multicolumn{3}{c}{ Aqueous phase containing Ca and Ni } \\
\cline { 2 - 7 } & $\mathbf{F S}_{\mathbf{C a}}$ & $\mathbf{F S}_{\mathbf{N i}}$ & $\mathbf{F S}_{\mathbf{C a}} / \mathbf{F S}_{\mathbf{N i}}$ & $\mathbf{F S}_{\mathbf{C a}}$ & $\mathbf{F S}_{\mathbf{N i}}$ & $\mathbf{F S}_{\mathbf{C a}} / \mathbf{F S}_{\mathbf{N i}}$ \\
\hline 3.5 & 0.6 & 0.2 & 2.9 & 0.7 & 0.2 & 3.0 \\
4.0 & 0.9 & 0.9 & 1.0 & 0.7 & 0.2 & 3.7 \\
4.5 & 1.3 & 0.5 & 2.8 & 1.2 & 0.04 & 32.6 \\
5.0 & 2.2 & 0.5 & 4.4 & 2.3 & 0.8 & 2.9 \\
5.5 & 4.9 & 0.7 & 7.3 & 3.1 & 2.9 & 1.1 \\
6.0 & 5.1 & 0.9 & 5.9 & 3.0 & 3.1 & 1.0 \\
6.5 & 1.1 & 0.6 & 1.9 & 4.1 & 1.9 & 2.2 \\
7.0 & 2.3 & 0.7 & 3.4 & 4.7 & 5.2 & 0.9 \\
\hline
\end{tabular}

are $0.05 \mathrm{~mol} \cdot \mathrm{L}^{-1}$, while exceeding the extractant molecules form micelles through polymerization in the bulk organic phase. It is also known that D2EHPA is fully protonated in the whole $\mathrm{pH}$ range investigated $\left(\mathrm{pK}_{\mathrm{a}}=1.35\right.$, Biswas et al., 2003), whereas $\mathrm{pK}_{\mathrm{a}}=3.26$ for Cyanex 272 (Biswas et al., 2005), consequently it may not be active for metal extraction at lower $\mathrm{pH}$ conditions. Therefore, the presence of nonprotonated molecules of Cyanex 272 occupying the interface at lower $\mathrm{pH}$ conditions may hinder metal extraction because only D2EHPA can extract metals at such conditions; at higher $\mathrm{pH}$ values, however, both extractants can actively extract the metals.

\section{CONCLUSIONS}

In the operating conditions studied, the extraction of calcium and/or nickel with Cyanex 272 and/ or D2EHPA followed typical behavior of cationic extractants, that is, metal extraction increased with $\mathrm{pH}$ of the aqueous phase, where calcium was extracted at lower $\mathrm{pH}$ levels than nickel. D2EHPA extracted more calcium or nickel $\left(\mathrm{pH}_{1 / 2, \mathrm{Ca}}<3.5\right.$ and $\left.\mathrm{pH}_{1 / 2, \mathrm{Ni}}=4.7\right)$ than Cyanex $272\left(\mathrm{pH}_{1 / 2, \mathrm{Ca}} \stackrel{1 / 2 \mathrm{C}}{=} 6.7\right.$ and $\left.\mathrm{pH}_{1 / 2 \mathrm{Ni}}>7.0\right)$ for a given $\mathrm{pH}$ level due to the stronger acidic character of phosphoric acid compared to the phosphinic acid.

Considering the metal competition in the aqueous phase, it has been observed that calcium extraction remains unaffected by the presence of nickel in equimolar metal concentration conditions, independently of the composition of the organic phase studied. As expected, no crowding out effect was verified. On the contrary, nickel extraction is displaced toward the right (higher $\mathrm{pH}$ values or lower extraction for a given $\mathrm{pH}$ level) in the presence of calcium when D2EHPA $\left(\Delta \mathrm{pH}_{1 / 2}=1.4\right)$ or Cyanex $272+$ D2EHPA $\left(\Delta \mathrm{pH}_{1 / 2}=0.9\right)$ are used.

Considering extractant competition in the organic phase, it has been observed that metal extractions (calcium and/or nickel) with Cyanex $272+$ D2EHPA follow quite closely the metal extraction curves obtained with D2EHPA alone. Therefore, D2EHPA acts as the main extractant agent, where synergism or antagonism effects are attributed to the presence of Cyanex 272.
For calcium, synergism (increase in calcium extraction) occurred at $\mathrm{pH} \geq 4.5$, being unaffected by the presence of nickel. For nickel, antagonism (rejection of nickel extraction) occurred in the whole $\mathrm{pH}$ range investigated in the absence of calcium, and at $\mathrm{pH}<5.5$ in the presence of calcium. For the operating conditions investigated, the separation of calcium from nickel is maximized at $\mathrm{pH}=4.5$ (calcium extraction > $80 \%$, nickel extraction $\left.<0.25 \%, \beta_{\mathrm{Ca} / \mathrm{Ni}}=2159\right)$.

\section{ACKNOWLEDGMENTS}

The authors wish to acknowledge CNPq (CT Mineral protocol $\mathrm{n}^{\circ} 550243 / 2011-9$ and PQ1C grant protocol $\mathrm{n}^{\circ}$ 304050/2016-4), CAPES-PROEX, FAPEMIG, INCT Acqua (National Institute of Science and Technology in Mineral Resources, Water, and Biodiversity, www.acqua-inct.org.br) for their financial support and Cytec Canada Inc. for providing samples of Cyanex 272.

\section{REFERENCES}

Agatzini-Leonardou, S., Tsakiridis, P.E., Oustadakis, P., Karidaris, T., and Katsiapi, A., Hydrometallurgical process for the separation and recovery of nickel from sulphate heap leach liquor of nickeliferrous laterite ores. Minerals Engineering, 22, 1181-1192 (2009). https://doi. org/10.1016/j.mineng.2009.06.006

Aguilar, M., and Cortina, J.L., Solvent extraction and liquid membranes: fundamentals and applications in new materials. 1.ed. London: CRC Press, 368p. (2010).

Biswas, R.K., Banu, R.A., and Islam, M.N., Some physico-chemical properties of D2EHPA. Part 2. Distribution, dimerization and acid dissociation constants in n-hexane $/ 1 \mathrm{M}\left(\mathrm{Na}^{+}, \mathrm{H}^{+}\right) \mathrm{SO}_{4}{ }^{2-}$ system, interfatial adsorption and excess properties. Hydrometallurgy, 69, 157-168 (2003). https://doi. org/10.1016/S0304-386X(02)00212-8

Biswas, R.K., Habib, M.A., and Singha, H.P., Colorimetric estimation and some physicochemical properties of purified Cyanex 272. Hydrometallury, 76, 97-104 (2005). https://doi.org/10.1016/j. hydromet.2004.09.005 
Biswas, R.K., and Singha, H.P., Purified Cyanex 272: its interfatial adsorption and extraction characteristics towards iron (III). Hydrometallurgy, 82, 63-74 (2006). https://doi.org/10.1016/j. hydromet.2006.03.002

Bukowsky, H., Uhlemann, E., Gloe, K., and Mühl, P., The separation of calcium and magnesium from lithium chloride by liquid-liquid extraction with di(2-ethylhexyl) phosphoric acid. Hydrometallurgy, 28, 323-329 (1992). https://doi.org/10.1016/0304386X(92)90037-Z

Cheng, C.Y., Solvent extraction of nickel and cobalt with synergistic systems consisting of carboxylic acid and aliphatic hydroxyoxime. Hydrometallurgy, 84, 109-117 (2006). https://doi.org/10.1016/j. hydromet.2006.05.002

Cheng, C.Y., Boddy, G., Zhang, W., Godfrey, M., Robinson, D.J., Pranolo, Y., Zhu, Z., and Wang, W., Recovery of nickel and cobalt from laterite leach solutions using direct solvent extraction: Part 1 - selection of a synergistic SX system. Hydrometallurgy, 104, 45-52 (2010). https://doi. org/10.1016/j.hydromet.2010.04.009

Cheng, C.Y., Urbani, M.D., Davies, M.G., Pranolo, Y., and Zhu, Z., Recovery of nickel and cobalt from leach solutions of nickel laterites using a synergistic system consisting of Versatic 10 and Acorga CLX 50. Minerals Engineering, 77, 17-24 (2015). https:// doi.org/10.1016/j.mineng.2015.01.015

Dutrizac, J.E., and Kuiper, A., The solubility of calcium sulphate in simulated nickel sulphatechloride processing solutions. Hydrometallurgy 82, 13-31 (2006). https://doi.org/10.1016/j. hydromet.2005.12.013

Flett, D.S., Solvent extraction in hydrometallurgy: the role of organophosphorus extractants. Journal of Organometallic Chemistry, 609, 2426-2438 (2005). https://doi.org/10.1016/j.jorganchem.2004.11.037

Guan, Q., Sun, W., Zhou, G., Liu, J., and Yin, Z., Recovery of cobalt and nickel in the presence of magnesium and calcium from sulfate solutions by Versatic 10 and mixtures of Versatic 10 and Cyanex 301. Transactions of Nonferrous Metals Society of China, 26(3), 865-873 (2016). https:// doi.org/10.1016/S1003-6326(16)64178-X

Guimarães, A.S., Silva, P.S., and Mansur, M.B., Purification of nickel from multicomponent aqueous sulfuric solutions by synergistic solvent extraction using Cyanex 272 and Versatic 10. Hydrometallurgy, 150, 173-177 (2014). https://doi. org/10.1016/j.hydromet.2014.10.005

Guimarães, A.S, and Mansur, M.B., Solvent extraction of calcium and magnesium from concentrate nickel sulfate solutions using D2HEPA and Cyanex 272 extractants. Hydrometallurgy, 173, 91-97 (2017). https://doi.org/10.1016/j.hydromet.2017.08.005

Guimarães, A.S, and Mansur, M.B., Selection of a synergistic solvent extraction system to remove calcium and magnesium from concentrated nickel sulfate solutions. Hydrometallurgy, 175, 250-256 (2018). https://doi.org/10.1016/j. hydromet.2017.12.001

Mantuano, D.P., Dorella, G., Elias, R.C.A., and Mansur, M.B., Analysis of a hydrometallurgical route to recover base metals from spent rechargeable batteries by liquid-liquid extraction with Cyanex 272. Journal of Power Sources, 159, 1510-1518 (2006). https://doi.org/10.1016/j. jpowsour.2005.12.056

Ndlovu, B., and Mahlangu, T., Calcium and magnesium rejection from sulphate solutions in lateritic nickel solvent extraction using Versatic 10 acid-LIX ${ }^{\circledR} 84$ IC system. Template Journal, 108, 223-227 (2008).

Preston, J., and Du Preez, A.C., Separation of nickel and cobalt from calcium, magnesium and manganese by solvent extraction with synergistic mixtures of carboxylic acids. The Journal of The Southern African Institute of Mining \& Metallurgy, 104(6), 333-338 (2004).

Preston, J., Solvent extraction of nickel and cobalt by mixtures of organophosphoric acids and non-chelating oximes. Hydrometallurgy, 11, 105-124 (1983). https://doi.org/10.1016/0304386X(83)90019-1

Preston, J., and Du Preez, A.C., Separation of nickel and calcium by solvent extraction using mixtures of carboxylic acids and alkylpiridines. Hydrometallurgy, 58, 239-250 (2000). https://doi. org/10.1016/S0304-386X(00)00135-3

Preston, J., and Du Preez, A.C., Solvent extraction of nickel from acidic solutions using synergistic mixtures containing pyridinecarboxylate esters. Part 1. Systems based on organophosphorous acids. J. Chem. Tech. Biotechol., 66(1), 86-94 (1996). https://doi.org/10.1002/ (SICI) 1097-4660(199605)66:1\%3C86::AIDJCTB456\%3E3.0.CO;2-9

Preston, J., and Du Preez, A.C., Synergistic effects in the solvent extraction of some divalent metals by mixtures of Versatic acid and pyridine carboxylate esters. J. Chem. Tech. Biotechol., 61(2), 159-166 (1994). https://doi.org/10.1002/jctb.280610211

Tsakiridis, P.E., and Agatzini, S.L., Process for the recovery of cobalt and nickel in the presence of magnesium and calcium from sulphate solutions by Versatic 10 and Cyanex 272. Minerals Engineering, 17, 535-543 (2004). https://doi.org/10.1016/j. mineng.2003.12.003 
